Relations industrielles

Industrial Relations

\title{
Industrial Relations in Canada, Second Edition, par Stuart Jamieson, Toronto, Macmilland of Canada, 1973, 156 pp.
}

\section{Gérard Dion}

Volume 28, numéro 4, 1973

URI : https://id.erudit.org/iderudit/028473ar

DOI : https://doi.org/10.7202/028473ar

Aller au sommaire du numéro

Éditeur(s)

Département des relations industrielles de l'Université Laval

ISSN

0034-379X (imprimé)

1703-8138 (numérique)

Découvrir la revue

Citer ce compte rendu

Dion, G. (1973). Compte rendu de [Industrial Relations in Canada, Second Edition, par Stuart Jamieson, Toronto, Macmilland of Canada, 1973, 156 pp.] Relations industrielles / Industrial Relations, 28(4), 902-902.

https://doi.org/10.7202/028473ar

Tous droits réservés @ C Département des relations industrielles de l'Université Laval, 1973
Ce document est protégé par la loi sur le droit d'auteur. L'utilisation des services d'Érudit (y compris la reproduction) est assujettie à sa politique d'utilisation que vous pouvez consulter en ligne.

https://apropos.erudit.org/fr/usagers/politique-dutilisation/ 
Nous avons rappelé que l'auteur a construit son recueil à partir de cas canadiens afin de tenir compte de certains caractères qui distinguent le Canada des Etats-Unis. Il ne faut pas oublier non plus que le Canada n'est pas un tout homogène et que ses diverses régions présentent des disparités économiques, culturelles, juridiques que l'auteur ne manque d'ailleurs pas de signaler brièvement dans son introduction. Il était éviderment illusoire de vouloir construire un recueil suggérant des cas qui seraient le reflet de cette diversité à moins d'en augmenter indûment le volume. L'auteur paraît avoir préféré porter son choix sur des thèmes à ce point classiques qu'ils évoquent des problèmes susceptibles de surgir sous n'importe laquelle des onze juridictions canadiennes en matière de relations du travail. A cet égard, au niveau de l'utilisation du recueil en discussion, il serait sans doute intéressant de tenir compte, entre autres, des différences au niveau des cadres juridiques qui régissent les relations du travail au Canada. On peut se demander, par exemple, dans quelle mesure la solution (décision arbitrale ou autre) aurait été la même si le problème s'était posé dans telle juridiction plutôt que dans telle autre. Nous pensons par exemple au cas des sous-contrats s'il s'était produit en contexte québécois compte tenu de l'article 36 du Code du travail.

Comme on peut le voir, les possibilités d'utilisation de ce recueil sont sans doute plus grandes que celles qu'on peut soupçonner au prernier coup d'oeil.

C'est à l'usage qu'on pourra mieux en juger mais si l'on en croit l'expérience de l'auteur dans l'élaboration et l'expérimentation de cet ouvrage avant sa publication, les responsables de l'enseignement en relations industrielles disposent d'un instrument dont la nécessité se faisait sentir depuis déjà longtemps et qui paraît très prometteur.

Université Laval

Jean BERNIER

Industrial Relations in Canada, Second Edition, par Stuart Jamieson, Toronto, Macmilland of Canada, 1973, $156 \mathrm{pp}$.

Cet ouvrage est la seconde édition du volume publié sous le même titre en 1957 que nous avions alors recensé dans
Relations industrielles. A cette époque nous avions noté que le titre ne correspond pas au contenu, car il s'agit bien seulement d'une étude sur le syndicalisme au Canada. Comme, en raison de sa valeur, l'ouvrage a connu un succès tel qu'il était déjà épuisé depuis plusieurs années, l'éditeur a tenu à conserver le même titre.

Dans cette nouvelle édition, l'auteur, tout en conservant la substance de son texte précédent, l'a considérablement remanié et mis à jour pour tenir compte de l'évolution du monde syndical ainsi que des mutations qui se sont produites dans notre milieu. Il a tiré profit des nombreuses études qui ont été faites et y a intégré une partie de ses propres recherches sur les conflits du travail effectuées pour le compte de l'Equipe spécialisée en relations de travail. Jamieson présente plutôt un nouveau volume, puisque près de la moitié de son texte est original.

Après une brève introduction décrivant le contexte économique et social affectant le régime des relations du travail au Canada, l'auteur consacre cinq chapitres à son sujet: origine et développement du mouvement syndical canadien; structure, gouvernement et politiques du syndicalisme canadien; malaises ouvriers et conflits industriels 1900-1972; rétrospective sur les conflits industriels; politique gouvernementale. Il termine avec une bibliographie choisie.

Il est impossible dans un ouvrage aussi bref de faire l'histoire du syndicalisme au Canada et de traiter en profondeur son orientation, son rôle, son action et les problèmes auxquels il a été mêlé. Le pays est trop vaste et les situations varient d'une province à l'autre. Nous notons avec satisfaction que l'auteur a accordé une attention particulière à la spécifité du syndicalisme au Québec.

En dépit de certains raccourcis inévitables et de certaines simplifications, on trouvera dans l'étude du professeur Jamieson la meilleure synthèse permettant de connaître le syndicalisme au $\mathrm{Ca}$ nada. Nous espérons que cet ouvrage sera traduit en français pour lui assurer la large diffusion qu'il mérite.

Université Laval
Gérard DION 